\title{
Analysis of Rocky Desertification in Central Guizhou, China, Using Landsat Satellite Data
}

\author{
S.P. Luo \\ Soil and Water Conservation Technology Consulting and \\ Research Center of Guizhou Province, Guiyang \\ Guizhou, China
}

\author{
J.R. Hu, Y.Z. Zhang \\ Institute of Space and Earth Information Science, The \\ Chinese University of Hong Kong, Shatin, N.T., Hong Kong \\ Laboratory of Coastal Zone Studies, Shenzhen Research \\ Institute, Virtual University Campus \\ Shenzhen China
}

\begin{abstract}
Rocky desertification is a typical type of land degradation in the Southwestern China. It has great economical and ecological implications for the local people. Landsat images for Qingzhen city of Guizhou Province collected in 2000, 2005 and 2010 were used for Karst rocky desertification monitoring. The results show that the good protected area is mainly distributed in the central, south, northeast and north of Qingzhen city; mild area is mainly distributed in the west and southwest of Qingzhen city; moderate area is mainly distributed in the northwest of Qingzhen city; intense area is mainly distributed in the central of Qingzhen city. The results also show that the distribution of RD areas increased from 2000 to 2005 , but slightly slow down from 2005 to 2010 . However, the rocky desertification in the study area still gets worse, though the rate slow since 2005 due to governmental land protection policies.
\end{abstract} region

Keywords-rocky desertification; landsat TM/ETM+; karst

\section{INTRODUCTION}

Rocky desertification (RD) is a process of land degradation involving serious soil erosion, extensive exposure of basement rocks, drastic decrease of land productivity and the appearance of a desert-like landscape [1]. Recent investigations suggest that RD is one main type of land desertification which is caused by irrational human impact on the vulnerable eco-geoenvironment [2]. It is one of the most serious land degradation problems in Karst areas especially in central Guizhou of southwest China, which is usually regarded as an obstacle to the local sustainable development.

Most areas in the central part of Guizhou Province belong to the Karst region. In Guizhou Province, the area of Karst regions is about $3.5 \times 104 \mathrm{~km}^{2}$, which is over $20 \%$ of the area of the total Province [2]. Similar to the other Karst areas in the southwest China, the geological environment is extremely fragile and sensitive, the area is overpopulated and the economy is backward [3].This has led to serious land degradation in the form of rocky desertification. The productivity of agriculture, forestry and livestock husbandry are threatened and this is making survival difficult. Rocky desertification is seriously constraining the sustained development of central Guizhou of south western China[4]. This issue has attracted wide attentions of the society. Many researches have focused on the process of $\mathrm{RD}$, including the ecological-environmental effects, and integrated rehabilitation $[5,6,7]$. However, the investigation of the RD and its change monitoring are absolutely significantly and also necessarily meaningful.

In this study, one typical karst region-Qingzhen city, which lies in the central of Guizhou Province was selected as the study area to monitoring rocky desertification change in Karst region. The Landsat TM/ETM+ data of 2000, 2005 and 2010 were downloaded to complete rocky desertification monitoring in Qingzhen city.

\section{STUDY AREA}

The study area, named Qingzhen, which was selected because it is located in Guizhou province, which is one main karst rocky desertification area in southwestern China. It is one of the largest Karst geomorphology distributing areas in the world, with an extremely fragile ecological environment. Qingzhen city lies in the central section of Guizhou province, ranging from $106^{\circ} 07^{\prime}$ to $106^{\circ} 33^{\prime} \mathrm{E}$ and from $26^{\circ} 24^{\prime}$ to $26^{\circ} 56^{\prime} \mathrm{N}$. Its land area is $1492.40 \mathrm{~km}^{2}$. However karst distributing area is about $1277.15 \mathrm{~km}^{2}$, which covered $85.62 \%$ of total land area (Qingzhen County Annals, 1985). It has complete morphologic types of karst landform, and belongs to typical karst city (region) area. The study area has a humid monsoon climate of north subtropics with an average annual temperature of $14.0^{\circ} \mathrm{C}$ (average maximum $34.5^{\circ} \mathrm{C}$ and average minimum $-8.6^{\circ} \mathrm{C}$ ). Total annual precipitation in the area is about $1200 \mathrm{~mm}, 77.3 \%$ of which comes between April and October, and terrain in this area has an elevation between $1240 \mathrm{~m}$ and $1452 \mathrm{~m}$ above sea level [8]. See Fig. 1.

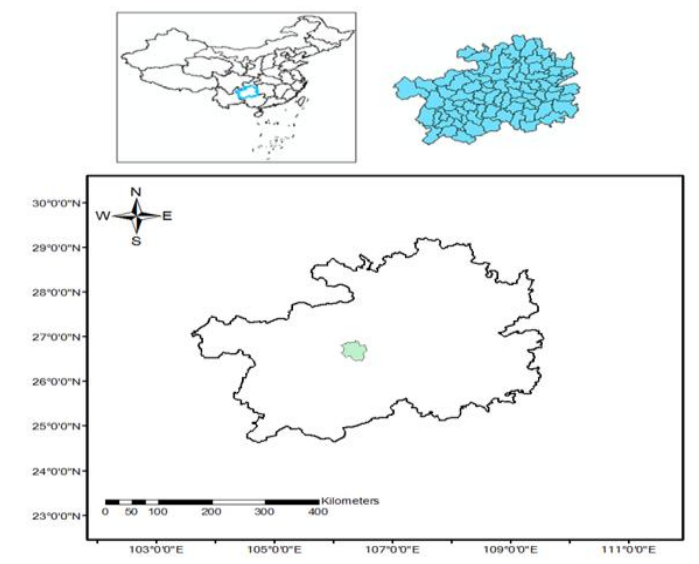

FIGURE I. LOCATION MAP OF THE STUDY AREA IN GUIZHOU PROVINCE, CHINA. 


\section{DATA AND METHODOLOGY}

\section{A. Data}

In this study, five kinds of data were used to setup the rocky desertification extent maps: (1) three scenes of remote sensing imagery for the years 2000, 2005 and 2010 Landsat TM data were used; it is acquired in Nov. 4th,2000 (WRS2:Path127/Row41， Path127/Row42),Oct. 9th,2005 (WRS2:Path127/Row41, Path127/Row42), and Oct. 31th, 2010 (WRS2: Path127/Row41, Path127/Row42), by Landat-5(TM), $5(\mathrm{TM})$ and 7(ETM+), respectively; (2) land use maps of 2000,2005 and 2010 with a scale of 1:100,000; (3) a common topographic map of $1: 140,000$ scale of Qingzhen city; (4) geological map of 1:1,500,000 scale of Guizhou Province; (5) And other data sources included vector data, administrative maps, some information from previous research and the yearbook of Guizhou. The landsat data were downloaded from the USGS Earth Resources Observation and Science (EROS) Center; land use maps, topographic map and geological map were downloaded from Chinese Natural Resources Database.The boundary vector data of the study area is from the National Fundamental Geographic Information System with a scale of 1:4,000,000. It contains the information of borders (national, province, city, county), rivers (the first, second, third class), main roads, main railways, and residences (e.g., city and county). In this study, the border and residence data are mainly used. In addition, local administrative maps, information from previous research and the yearbooks of Guizhou are used as supporting data in the study.

\section{B. Methodology}

The processing procedures of this study totally including five steps. Firstly, the geometric correction of Landsat TM $(\mathrm{ETM}+)$ data was processed with topographic map as the base map to select the ground control points (GCPs) to correct the image of 2000, then do the registration the images of 2005 and 2010 with the corrected image of 2000 , the root mean square error (RMSE) of registration process is less than half pixel. Then, the images were projected to the same coordinate system and implement the mosaic process after geo-reference calibration. Secondly, the study area of Qingzhen City was retrieved using the border vector data. Thirdly, non-carbonate distribution region, water and some other non-karst regions were masked as part of good protected area in later RD extent classification aid with the geological map and land use maps of Qingzhen city. Fourthly, NDVI was calculated to identify the extent of RD from Landsat data. Finally, to distinguish the extent of the RD from 2000 to 2010, a decision tree upon Table 1 was produced as shown in Fig. 2. And then, the rocky desertification change area was counted and analyzed.

The normalized difference vegetation index (NDVI) [9] is one of the most extensively applied vegetation indices for its sensitivity to the presence, density and condition of vegetation. It is a simple numerical indicator that can be used to analyze remote sensing measurements. NDVI provides a crude estimate of vegetation health and a means of monitoring changes in vegetation over time. Vegetation index is extracted from the multi-spectral remote sensing data, it can quantized reflect the plants situation and helps strengthen our interpretation of remote sensing images. As a means of remote sensing, it is widely used in monitoring land-use cover, vegetation cover, density assessment, crop identification and crop forecasting. It has enhanced the ability of the classification in the topic mapping [10].

The vegetation index is linear correlation to vegetation distribution density[11].The bigger of NDVI, the better of vegetation cover; the lower of the NDVI, the more serious of RD. Based on this assumption, the RD extent was determined in the study area from 2000 to 2010 .

The formula for NDVI [12] calculation can be expressed as follows:

$$
\mathrm{NDVI}=\left(\mathrm{R}_{\text {nir }}-\mathrm{R}_{\mathrm{red}}\right) /\left(\mathrm{R}_{\mathrm{nir}}+\mathrm{R}_{\mathrm{red}}\right)
$$

Where, Rnir in the formula is the reflectance of near infrared band and Rred the reflectance of the red band, corresponding to the fourth band and the third band of Landsat $\mathrm{TM} / \mathrm{ETM}+$ data, respectively.

TABLE I. THE RELATIONSHIP OF NDVI AND THE EXTENT OF RD [13].

\begin{tabular}{c|cccc}
\hline $\begin{array}{c}\text { NDVI } \\
\text { value }\end{array}$ & $<0.2$ & $0.2-0.4$ & $\begin{array}{c}0.4- \\
0.6\end{array}$ & $>0.6$ \\
\hline \multirow{2}{*}{ RD extent } & Intensity & Moderate & Mild & $\begin{array}{c}\text { Good } \\
\text { protected }\end{array}$
\end{tabular}

There is a relationship between NDVI and the extent of RD as shown in Table 1. From the table, one can see that if NDVI value is below 0.2 , it means there is little vegetation cover on this area, and much rocky land exposed to the air, so the RD here is intense; if the NDVI value is between 0.2 and 0.4 , the extent of RD is moderate; if NDVI is between 0.4 and 0.6 , the extent of RD is mild; when the NDVI is above 0.6, it means these areas are good protected.

NDVI values were calculated by equation (1) and their distribution maps of 2000, 2005 and 2010 were obtained using ENVI software. To obtain the classification results of RD extent from 2000 to 2010, a decision tree based on Table1 and previous research [14] was conducted as showed in Fig.2.

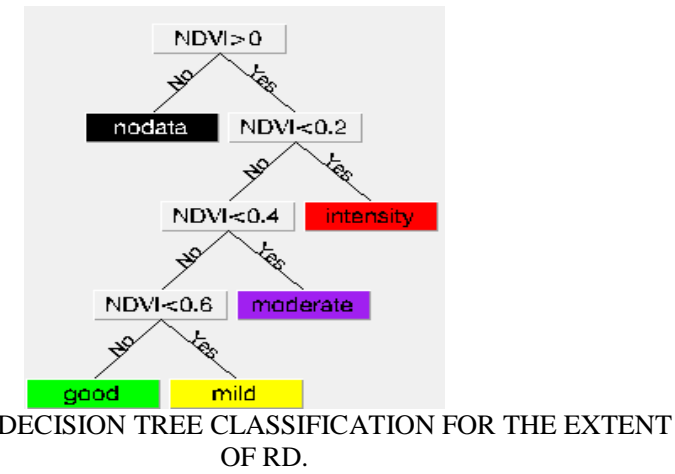

\section{RESULTS AND DISCUSSIONS}

The extent distribution of RD from 2000 to 2010 is mapped in following Fig.3, the counted area and percentage of each RD type was showed in table 2. Statistics from table 2 show that rocky desertification area makes up $24.9 \%, 25.57 \%$ and $25.18 \%$ of Qingzhen city's total area in 2000, 2005 and 2010, respectively. From Fig.3, it is clear that good protected area is 
mainly distributed in the central, south, northeast and north of Qingzhen city; mild area is mainly distributed in the west and southwest of Qingzhen city; moderate area is mainly distributed in the northwest of Qingzhen city; intense area is mainly distributed in the central of Qingzhen city.

Compare the results of table 2 from 2000,2005 and 2010, it is clearly found that good protected area has a slightly decrease from 2000 to 2005, and then a little increase from 2005 to 2010; the mild RD area is decreasing significantly from 2000 to 2005 and then increasing from 2005 to 2010 in the west part of the study area; the moderate RD area increasing from 2000 to 2005 and decreasing from 2005 to 2010. Whilst, intense RD area basically keep stable during 2000 and 2010,it indicates that the environment of the study area does not deteriorate very badly. From table 2, it is clear that good protected area decreased from 2000 to 2005 and increased again from 2005 to 2010, while intense areas are relatively stable, and mild area decreased remarkably from 2000 to 2005 and has a notable increase from 2005 to 2010. The moderate area just has the opposite trend with the mild area, it has an obviously increase from 2000 to 2005 and has a marked decline from 2005 to 2010.This indicates that some mild areas have been converted to moderate areas during 2000 and 2005, while there is some moderate area converted into mild areas since 2005 due to governmental land protection policies.

However, the study results indicate that the Karst rocky desertification in the study area still gets worse, irrational land use in this region is still exist, though the rate reduced since 2005 due to governmental land protection policies.

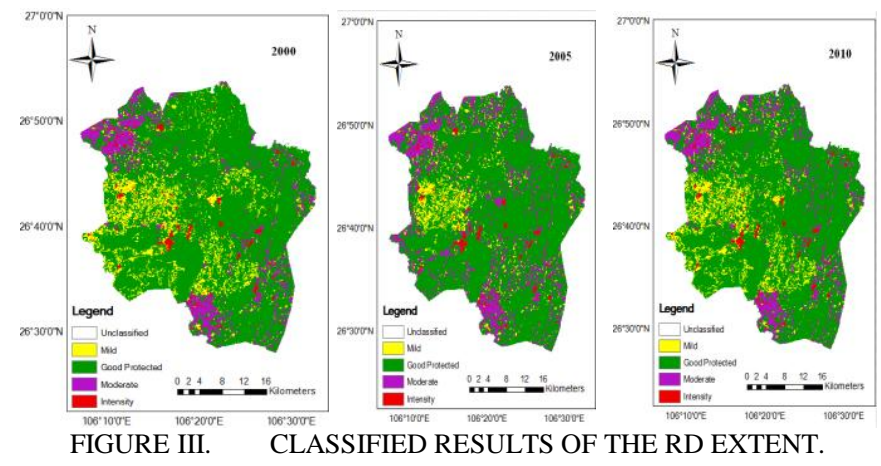

TABLE II. THE AREA AND PERCENT OF EACH RD EXTENT IN $2000,2005,2010$.

\begin{tabular}{lrrrcc}
\hline Year & Type & Intens & Moder & mild & Good \\
\hline \multirow{2}{*}{2000} & Percent $(\%)$ & 0.90 & 6.25 & 17.75 & 75.10 \\
& Area $\left(\mathrm{km}^{2}\right)$ & 13.43 & 93.28 & 264.90 & 1120.79 \\
\multirow{2}{*}{2005} & Percent $(\%)$ & 1.07 & 8.36 & 16.14 & 74.43 \\
& Area $\left(\mathrm{km}^{2}\right)$ & 15.97 & 124.76 & 240.87 & 1110.79 \\
& Percent $(\%)$ & 0.94 & 6.99 & 17.25 & 74.82 \\
\hline
\end{tabular}

\section{V.CONCLUSIONS}

In this study, Landsat TM/ETM+ data with $30 \mathrm{~m}$ resolution were used to monitor the RD change in central of Guizhou Province from 2000 to 2010. NDVI calculation method was performed to detect the RD extent. This method is based on the relationships between NDVI and RD. In general, if NDVI value of a region is high, it means the vegetation cover is well protected with a rare extent of RD. Otherwise From the above results, the distribution of RD areas increased from 2000 to 2005 and reduced from 2005 to 2010. The results show that good protected area is mainly distributed in the central, south, northeast and north of Qingzhen city; mild area is mainly distributed in the west and southwest of Qingzhen city; moderate area is mainly distributed in the northwest of Qingzhen city; intense area is mainly distributed in the central of Qingzhen city. It is also shows that rocky desertification area makes up $24.9 \%, 25.57 \%$ and $25.18 \%$ of Qingzhen city's total area in 2000, 2005 and 2010, respectively. It indicates that the Karst rocky desertification in the study area still gets worse, though the rate reduced since 2005 due to governmental land protection policies. This study results also tells us that the process of Karst rocky desertification is nearly irreversible; few of Karst rocky desertification could be converted into nondesertification land. However, it is reported that $37.6 \% \mathrm{RD}$ is resulted from natural factors, while $62.4 \%$ of the RD area is caused by direct human activities[15].Therefore, it is urgent to propagate scientific knowledge on environment protection in the Karst area, and some other effective control measures should be taken, like development of the biogas construction, population growth controlling, industrial pollution prevention, and so on.

\section{ACKNOWLEDGEMENTS}

The Landsat TM/ETM+ data downloaded from website of USGS Earth Resources Observation and Science (EROS) Center. This research was partly supported by Prof. Yulun An's Project, Guizhou Normal University (GY No.(2007)3017) and Hong Kong RGC GRF (CUHK 459210) project.

\section{REFERENCES}

[1] Yang H. Karst rocky desertification and assessment of the disasters. Mar Geol Quaternary Geol 15:137-147, 1995.

[2] Wang S, Liu Q. Karst rocky desertification in southwestern China: geomorphology, land use, impact and rehabilitation.Land Degrada Develop 15:115-121, 2004.

[3] Ma W.H. Sustainable development of vulnerable karst ecological environment in Guizhou, Journal of Guizhou Normal University (Natural Sciences), (21)2:75-79, 2003.

[4] Wang S, Liu Q. Karst rocky desertification in southwestern China: geomorphology, land use, impact and rehabilitation.Land Degrada Develop 15:115-121, 2004.

[5] Wang S. J. The most serious eco-geologically environmental problem in southwestern China Karst rocky desertification. Bulletin of Mineralogy Petrology and Geochemistry,22(2): 120-126, 2003.

[6] Wang S. J, Li Y B. Karst rocky desertification: formation background, evolution and comprehensive taming. Quaternary Sciences, 23(6): 657$666,2003$.

[7] Cai Y. L. The Study of Alleviating Poor and Sustainable Development in Southwest Karst Area. Beijing: Peking University Press , 1994.

[8] Wang S J, Liu Q. M, Zhang D. F. Karst rocky desertification insouthwestern China: geomorphology, land use, impact and 
rehabilitation. Land Degradation and Development, 15(2):115-121, 2004.

[9] Mei Z.M.and Xiong K.N. A study on the dynamic characteristics of soil erosion and eco-benefit evaluation in karst region-A Case Study on Qingzhen Demonstrating Site of Returning Farmland to Wood(Grass), Guizhou, Carsologica Sinica, 22(2): 136-143, 2003.

[10] Herrmann, S, Anyamba, A. and Tucker, C. Recent trends in vegetation dynamics in the African Sahel and their relationship to climate. Global Environmental Change, 15,pp. 394-404, 2005.

[11] Du L. Preprocessing and NDVI calculation of MODIS 1B data. Desert and Oasis Meteorology, 2(1), 26-28, 2008.

[12] Zhang Y.Z.,Hu J.R. Analysis of Rocky Desertification Monitoring Using MODIS Data in Western Gugangxi,China.In:Geoscience (ISBN 978953-307-109-0),299-312, 2011.

[13] Zhang H.,Zhou Z.F. and Xie J. Karst Rocky Desertification of Extracting Vegetation Coverage Inversion Based on NDVI Serial Images and dimidiate pixel model. Remote Sensing Image Processing, Geographic Information Systems, and Other Applications, edited by Jianguo Liu, Jinwen Tian,doi: 10.1117/12.901796,80060M1-80060M6, 2011.

[14] Hu B., Liao C, Yan Z., Jiang, S. Diving Mechanism Diagnosis of Karst Rocky Desertification in Du'an Yao Autonomous County of Guangxi based on RS and GIS. Journal of Mountain Science, 22(5). 583-590, 2004.

[15] Nong S. Rock desertification status analysis in karst areas of Guangxi and control measures. Guangxi Forestry Science, 36(3), 170-172, 2007. 